\title{
Variations in early life history traits of Japanese anchovy Engraulis japonicus in the Yangtze River Estuary
}

\author{
Chunlong Liu ${ }^{1}$, Weiwei Xian ${ }^{\text {Corresp., }}{ }^{1,2}{ }^{\text {, Shude Liu }}{ }^{1}$, Yifeng Chen ${ }^{3}$ \\ ${ }^{1}$ CAS Key Laboratory of Marine Ecology and Environmental Sciences, Institute of Oceanology, Chinese Academy of Sciences, Qingdao, China \\ 2 Laboratory for Marine Ecology and Environmental Science, Qingdao National Laboratory for Marine Science and Technology, Qingdao, China \\ 3 Laboratory of Biological Invasion and Adaptive Evolution, Institute of Hydrobiology, Chinese Academy of Sciences, Wuhan, China \\ Corresponding Author: Weiwei Xian \\ Email address: wwxian@qdio.ac.cn
}

Resources of Japanese anchovy are undergoing dramatic recessions in China as the consequence of intensifying anthropogenic activities. Elucidating the influences of localscale environmental factors on early life history traits is of great importance to design strategies conserving and restoring the declining anchovy resources. In this research, we studied hatching date and early growth of anchovy in the Yangtze River Estuary (YRE) using information obtained from otolith microstructure. Onset of hatching season and growth rates of anchovy was compared to populations in Japan and Taiwan. In YRE, hatching date of anchovy ranged from February $26^{\text {th }}$ to April $6^{\text {th }}$ and mean growth rate ranged from 0.27 to $0.77 \mathrm{~mm} / \mathrm{d}$. Anchovy hatching later had higher growth rates than individuals hatching earlier before the $25^{\text {th }}$ day. Among populations, hatching onsets of anchovy in higher latitude were later than populations in lower latitude, and growth rates of anchovy in YRE were much lower than populations in Japan and Taiwan. Variations in hatching onset and early growth patterns of anchovy thus provide important knowledge on understanding the adaptation of anchovy in YRE and designing management strategies on conserving China's anchovy resources. 
1 Variations in early life history traits of Japanese anchovy Engraulis japonicus in the

3 Chunlong Liu ${ }^{1}$, Weiwei Xian ${ }^{1,2}$, Shude Liu ${ }^{1}$, Yifeng Chen $^{3}$

\section{Address:}

$6{ }^{1}$ CAS Key Laboratory of Marine Ecology and Environmental Sciences, Institute of Oceanology,

7 Chinese Academy of Sciences, Qingdao 266071, China

$8 \quad{ }^{2}$ Laboratory for Marine Ecology and Environmental Science, Qingdao National Laboratory for

9 Marine Science and Technology, Qingdao 266071, China

$10{ }^{3}$ Laboratory of Biological Invasion and Adaptive Evolution, Institute of Hydrobiology, Chinese

11 Academy of Sciences, Wuhan 430072, China

13 *Correspondence author E-mail: wwxian@qdio.ac.cn

14 Postal address: Key Laboratory of Marine Ecology and Environmental Sciences, Institute of

15 Oceanology, Chinese Academy of Sciences, Qingdao 266071, China

16 Running title: Early life history of Japanese anchovy 
17 TITLE: Variations in early life history traits of Japanese anchovy Engraulis japonicus in the

18 Yangtze River Estuary

19 ABSTRACT: Resources of Japanese anchovy are undergoing dramatic recessions in China as

20 the consequence of intensifying anthropogenic activities. Elucidating the influences of local-

21 scale environmental factors on early life history traits is of great importance to design strategies

22 conserving and restoring the declining anchovy resources. In this research, we studied hatching

23 date and early growth of anchovy in the Yangtze River Estuary (YRE) using information

24 obtained from otolith microstructure. Onset of hatching season and growth rates of anchovy was

25 compared to populations in Japan and Taiwan. In YRE, hatching date of anchovy ranged from

26 February $26^{\text {th }}$ to April $6^{\text {th }}$ and mean growth rate ranged from 0.27 to $0.77 \mathrm{~mm} / \mathrm{d}$. Anchovy

27 hatching later had higher growth rates than individuals hatching earlier before the $25^{\text {th }}$ day.

28 Among populations, hatching onsets of anchovy in higher latitude were later than populations in

29 lower latitude, and growth rates of anchovy in YRE were much lower than populations in Japan

30 and Taiwan. Variations in hatching onset and early growth patterns of anchovy thus provide

31 important knowledge on understanding the adaptation of anchovy in YRE and designing

32 management strategies on conserving China's anchovy resources. 


\section{INTRODUCTION}

38 Japanese anchovy (Engraulis japonicus Temminck \& Schlegel, 1846) is a widespread fish in the

39 northwest Pacific Ocean with great contributions to fishery resources and ecosystem functions

40 (Zhao et al., 2003; Takasuka \& Aoki, 2006; Wan \& Bian, 2012). As the keystone species in

41 coastal and marine ecosystems, anchovy plays the crucial role on connecting different trophic

42 levels by acting as the predator for plankton and the prey for piscivorous fishes (Iseki \&

43 Kiyomoto, 1997; Kim \& Lo, 2001; Wang et al., 2006; Hsieh et al., 2009). Due to the high

44 susceptibility to environmental changes, anchovy resources exhibit remarkable fluctuations

45 across years and regions (Takahashi et al., 2001; Takasuka et al., 2007). Elucidating the

46 mechanisms responsible for fluctuations of anchovy resources is thus important to develop

47 strategies for conserving coastal and marine biodiversity. Despite of the profound impacts of

48 climatic factors on anchovy resources (Kim \& Lo, 2001; Hsieh et al., 2009), local-scale

49 environmental factors (e.g. sea surface temperature and habitat quality) are also the key

50 determinants on dynamics of anchovy population, which has been well studied in Japan, Korea

51 and Taiwan (Chen \& Chiu, 2003; Takahashi \& Watanabe, 2004; Takasuka et al., 2007).

52 However in mainland China, the region owning the widest distributions and largest catches of

53 anchovy (Fisheries and Aquaculture Department, FAO, Rome, Italy; available:

54 http://www.fao.org/home/en/), little effort was paid to explore the influence of local

55 environmental factors on anchovy populations (but see Zhu et al., 2007).

56 Early life history in larval stage is the "window" in which fish has the highest vulnerability 
57 and mortality rates (Takasuka et al., 2003; Takahashi \& Watanabe, 2004; Starrs et al., 2016). In

58 early life history, growth rate is the main factor determining larval duration and mortality, which

59 are both closely related to recruitment strength (Takasuka et al., 2003; Takahashi \& Watanabe,

60 2004; Starrs et al., 2016). Within a population, fish with faster growth could gain the larger size

61 by accelerating the development and metamorphosis compared to other individuals from the

62 same cohort, consequently having the shorter larval duration and higher survival rate ("growth-

63 mortality" hypothesis; Takahashi et al., 2001; Hwang et al., 2006; Takasuka \& Aoki, 2006; Itoh

64 et al., 2011). Early growth of anchovy is significantly affected by local environmental factors

65 and even slight environmental changes might cause great variations in population mortality and

66 the amount of recruitments into the adult population (Takahashi et al., 2001; Chen \& Chiu,

67 2003; Takahashi \& Watanabe, 2004; Hwang et al., 2006; Zenitani et al., 2009). Water

68 temperature is one of the most important factors affecting anchovy early growth (Hwang et al.,

69 2006; Takasuka et al., 2007). When temperature is lower than the optimal growth temperature,

70 higher temperature would consistently accelerate fish growth by improving individual metabolic

71 rate (Hwang et al., 2006; Takasuka et al., 2007). In addition, a number of studies have

72 emphasized the importance of habitat quality on fish growth (e.g. Amara et al., 2007; Amara et

73 al., 2009). The degradation in habitat quality decelerates fish growth through reducing food

74 availability and directing fish to devote more energy for tolerating higher pollution (Amara et al.,

75 2007; Amara et al., 2009). Understanding variations in early growth of anchovy under different

76 environments could therefore provide crucial insights on predicting population dynamics and 
77 estimating the year-class recruitment strength (Takasuka et al., 2007).

78 China's anchovy resources are undergoing dramatic declines as the consequence of dam

79 construction, intensified overfishing and water pollution (Zhao et al., 2003; Zhu et al., 2007).

80 The recession in anchovy resources is especially striking between 1993 and 2002, with annual

81 catch rapidly decreasing from 4.12 to 0.18 million tons, posing significant threats to fishery

82 economy and ecosystem functions (Zhao et al., 2003). To conserve and restore the declining

83 anchovy resources, it's urgently needed to design applicable management strategies to ensure the

84 success of population recruitment based on the adaptivity of anchovy to China's environments

85 (Hwang et al., 2006; Wang et al., 2006). In consideration of the key role of growth in the process

86 of population recruiting, determining the impacts of environmental changes on early growth

87 could shed important lights on elucidating anchovy adaptivity in the early life history (Takasuka

$88 \&$ Aoki, 2006; Takasuka et al., 2007).

89 The Yangtze River Estuary (YRE) is an important spawning, feeding and nursery ground

90 for Japanese anchovy and other fishes benefiting from the high productivity contributed by

91 abundant sediments in the outflow of the Yangtze River (Zhou et al., 2008; Yu \& Xian, 2009;

92 Zhang et al., 2009). However, intensifying urbanization and increasing anthropogenic activities

93 are causing severe degradations of the aquatic ecosystem in the YRE, leading to remarkable

94 declines in anchovy resources (Jiao et al., 2007). To provide knowledge on the conservation of

95 anchovy resources in YRE, we aim for achieving two overarching targets using information

96 obtained from otolith microstructure: (1) to determine the growth pattern in early life history of 
97 anchovy from YRE; (2) to detect changes in anchovy early growth among groups with different

98 hatching dates and among populations across the northwestern Pacific Ocean. By revealing the

99 intra- and inter-population differences in early growth patterns, our study could contribute

100 valuable information to the development of cost-effective strategies on managing anchovy

101 resources in the highly exploited aquatic ecosystems of YRE.

102 MATERIALS AND METHODS

103 Field Sampling

104 Anchovy larvae were collected in May, 2012 in the "Spring investigation of fishery resources

105 and ecology in Yangtze River Estuary" survey. Forty stations were set from the mouth of the

106 Yangtze River to the offshore $\left(30^{\circ} 45^{\prime} \mathrm{N}-30^{\circ} 45^{\prime} \mathrm{N}, 122^{\circ} 20^{\prime} \mathrm{E}-123^{\circ} 20^{\prime} \mathrm{N}\right.$ ) (Xing et al., 2014; Li

107 et al., 2015). In this survey, environmental factors showed noticeable variations among stations,

108 indicating the very high physical and chemical heterogeneity in YRE. For example, the depth

109 ranged from 3 to $60 \mathrm{~m}$ and salinity ranged from 0.13 to 33.98\%o (Supplement 1 ). At each station,

110 a horizontal plankton net ( $0.8 \mathrm{~m}$ diameter with $0.5 \mathrm{~mm}$ mesh size) was towed at the surface with

111 a speed of two knots for ten minutes to sample anchovy. During this survey, anchovy were

112 collected in two stations (Station 29, 1129 individuals; Station 30, 1342 individuals). Sampled

113 larvae were immediately preserved in 90\% ethanol and taken back to the laboratory. All

114 specimens were collected in accordance with wild animal conservation law issued by the 
115 People's Republic of China for the purposes of conducting research on Japanese anchovy.

\section{Environmental data}

117 Data of daily sea surface temperatures (SST) in each station were obtained from NOAA SST

118 High Resolution Dataset (http://www.esrl.noaa.gov/psd/) to represent the water temperature

119 across anchovy growing seasons (from February $26^{\text {th }}$ to May $3^{\text {rd }}, 2012$; see Results). Daily SST

120 data are generated from an Advanced Very High Resolution Radiometer (AVHRR), which can

121 infer the precise SST at very high resolution $(1.09 \mathrm{~km})$ using multi spectral analysis. The time

122 series SST data allowed us to assess the influence of water temperature on anchovy growth by

123 comparing growth patterns among individual hatching on different dates.

\section{Otolith microstructure analysis}

125 A subset of 200 individuals were randomly selected from samples at Station 29 and 30. Standard

126 length (SL) of each individual was measured to the nearest $\mathrm{mm}$, and both right and left sagittal

127 otoliths were extracted from fish head under a dissecting microscope. Either the right or left otolith

128 was mounted on a slide using melting thermoplastic glue and polished with $15 \mu \mathrm{m}$ lapping film

129 until increments could be clearly interpreted (Wang \& Tzeng, 1999). Each unbroken otolith section

130 was photographed at $400 \times$ magnification using a digital camera fixed to a light microscope $(\mathrm{BH} 2$,

131 Olympus Optical Co. Ltd., Tokyo, Japan) to obtain the picture of each section with clear

132 increments. Numbers and widths of otolith increments were counted and measured along the 
133 maximum otolith radius (OR) from the nucleus to the edge using Increment Analysis Program

134 (Huazhong Agricultural University, Wuhan, Hubei Province, China). For each section, we made

135 two independent measurements on increment numbers. If the difference in two numbers differed

136 less than 5\%, one number was randomly selected as the increment number of this otolith; otherwise

137 the increment number was measured again. If the third number differed by $<5 \%$ compared to one

138 of the first two numbers, the third number was used as the increment number. If the third evaluation

139 still differed the first two numbers by $>5 \%$, that otolith section was discarded.

140 Data analysis

141 The daily age (D) of each individual was determined using the increment number plus three,

142 because the first increment of anchovy otolith is deposited on the fourth day after hatching (Tsuji

$143 \&$ Aoyama, 1984). Hatch dates were thus back-calculated by subtracting age from the catch date

144 (May $3^{\text {rd }}$ ). Daily somatic growth rates were back-calculated from increment width using the

145 biological intercept method (Campana, 1990), with the length at hatching $(5.6 \mathrm{~mm})$ as the

146 biological intercept (Tsuji \& Aoyama, 1984). Data normality test indicated that the variances of

147 SL and D were not equal for anchovy from two stations, and Wilcoxon signed-rank tests were

148 thus used to compare frequency distributions of both SL and D between stations. Linear

149 regression was used to fit relationships between SL and OR and between SL and D. Non-

150 parametric repeated measures analysis of covariance was performed to compare the relationship

151 of SL with D between two stations. Because of the significantly positive relationships between 
152 OR and SL (see Result), otolith increment widths were used as the proxy of anchovy early 153 growth.

154 Given the possible differences in early growth among individuals hatching on different

155 dates, anchovy from each station were divided into three nearly equal-sized groups according to

156 hatching dates for the comparison in otolith growth trajectory within population. Anchovy

157 hatching from February $26^{\text {th }}$ to March $16^{\text {th }}$ were categorized "early group", from March $17^{\text {th }}$ to

158 March $26^{\text {th }}$ as "middle group", and from March $27^{\text {th }}$ to April $6^{\text {th }}$ as "late group". A repeated

159 measures analysis of variance (RM-ANOVA) was used to compare otolith growth trajectories

160 among groups in each station (Searcy \& Sponaugle, 2000). Because the minimum age of

161 anchovy was 24 days, the level of RM-ANOVA was set at 24 to include all samples. The within-

162 subject factor was daily growth rate and the between-subject factor was group. Because the

163 distribution of increment widths was not normal, data of increment widths were log-transformed

164 before RM-ANOVA.

165 Compared to anchovy in YRE, populations in Japan and Taiwan should be less affected by

166 pollutions and overfishing due to the better conservation on coastal and marine environments

167 (Kim \& Lo, 2001; Chai et al., 2006; Wang et al., 2006; Takasuka et al., 2007). To assess the

168 difference in early growth of anchovy living under different habitat quality, mean growth rate of

169 each anchovy were calculated for the comparison in growth of anchovy in Japan and Taiwan. To

170 do so, we conducted the extensive searches on data of hatching onset and early growth rates from

171 scientific papers. Only studies reporting both two characters were kept. For each region, mean 
172 growth rates of anchovy in populations with earliest hatching dates were selected as

173 representative to compare growth of the first emerging individuals. Consequently, data of

174 anchovy in Taiwan (Chiu \& Chen, 2001) and Japan (Takahashi et al., 2001) were used for inter-

175 population comparisons. All the analyses were performed in R 3.2.0 (R Development Core

176 Team, 2014) using the packages sm (Bowman \& Azzalini, 2014).

\section{RESULTS}

178 There was a continuous increase in SST during anchovy growth season (Figure 1; Supplement 2).

179 SST rose from 6.2 to $16.6^{\circ} \mathrm{C}$ at Station 29 and from 6.7 to $16.0^{\circ} \mathrm{C}$ at Station 30 between $29^{\text {th }}$

180 February and $3^{\text {rd }}$ May. The consistent rising in SST indicated that the early, middle and late groups

181 experienced different thermal environments during their growing seasons.

182 SL and D of anchovy at Station 29 were both significantly lower than Station 30 (Figure2;

183 Table 1), demonstrating anchovy were larger and older in the offshore. Hatch dates ranged from

184 February $26^{\text {th }}$ to April $6^{\text {th }}$ at Station 29 , and from February $28^{\text {th }}$ to April $5^{\text {th }}$ at Station 30 (Figure

1852 2; Table 1). Growth rates of anchovy ranged from 0.27 to $0.77 \mathrm{~mm} / \mathrm{d}$ and from 0.29 to $0.73 \mathrm{~mm} / \mathrm{d}$

186 at Station 29 and 30 respectively (Table 1; Supplement 3). Relationships between SL and OR were

187 both significantly positive at two stations (both $p<0.01$ ). No significant difference was found in

188 the relationships of SL with D between two stations $(p>0.05)$, and the SL-D relationship were

189 described by a common regression equation for two populations: $\mathrm{SL}=0.386 \mathrm{D}+4.87\left(R^{2}=0.55\right.$,

$190 p<0.01)$. Despite of the overall similar patterns of increasing growth rates for three groups before 
191 the $25^{\text {th }}$ day, significant differences were found in growth trajectories between three groups at each

192 station (Station 29, all $p<0.05$; Station 30, all $p<0.05$ ), with anchovy hatching later showing

193 much faster growth (Figure 3). After the $25^{\text {th }}$ day, differences in growth trajectory among groups

194 became larger, with growth rates being highest for early groups and lowest for late groups.

195 The ranges of standard length were largely overlapped for three populations, suggesting the

196 similar ontogenic stage of anchovy from Japan, YRE and Taiwan (Table 2). There was a

197 countergradient pattern in hatching onsets among populations, with the onset being later with

198 increasing latitude in a rate of 15 d per five degrees. However, no consistent pattern was found

199 between growth rates and latitude. The minimum and maximum growth rates of anchovy from

200 YRE were both clearly lower than those of anchovy from Taiwan and Japan. The highest growth

201 rate of YRE population was even lower than the minimum growth rate of population in Japan.

\section{DISCUSSION}

203 Understanding the response of fish early growth to environmental changes is of great importance

204 to predict the strength of population recruitment and dynamics of fishery resources (Takasuka et

205 al., 2003; Takasuka \& Aoki, 2006). Comparing growth rates and growth patterns of individuals

206 from different populations or groups is a common way to investigate the influences of

207 environmental changes on fish early growth (Chen \& Chiu, 2003; Yasue \& Takasuka, 2009). In

208 this study, we found significant differences in early growth of anchovy hatching on different dates

209 and among populations from different regions. Variations in growth patterns on the temporal and 
210 spatial scales provide important knowledge on elucidating the adaptation of anchovy in YRE and

211 facilitating the conservation across the northwestern Pacific Ocean.

212 Hatching date is proven as the key factor affecting anchovy growth during the early life

213 history, with growth rates showing an increasing pattern with hatching date. Differences in early

214 growth of anchovy hatching on different dates have been reported for populations in the Yellow

215 Sea (Hwang et al., 2006) and the East China Sea (Takasuka \& Aoki, 2006). Increasing temperature

216 is attributed as the primary factor accelerating anchovy early growth. Growth rates of anchovy are

217 found positively related to temperature up to $20-26^{\circ} \mathrm{C}$ (Hwang et al., 2006; Takasuka \& Aoki,

218 2006). During the growth season beginning from February, SST in YRE rapidly rises from $6^{\circ} \mathrm{C}$ to

$21916^{\circ} \mathrm{C}$ in May, thus increasing growth rates by improving individual metabolic rate and prey

220 abundance. However, higher growth rates in the beginning may not compensate for the shorter

221 growing season of late-hatching anchovy because of their lower growth rates compared to early-

222 hatching anchovy after the $25^{\text {th }}$ day.

223 It is important to note that growth rates of anchovy in YRE are much lower than populations

224 in Japan and Taiwan. This result is unexpected as the high productivity in YRE should have

225 supported the faster early growth of anchovy (Zhou et al., 2008). Although there are difficulties

226 in determining the specific mechanisms, several factors might be responsible for lower growth

227 rates. First, polluted waters could decelerate fish growth by directing more energy toward the

228 tolerance of worse conditions (Amara et al., 2007; Amara et al., 2009). Aquatic ecosystems of

229 YRE are threatened by increasing anthropogenic activities and sewage discharges with an 
230 unparalleled magnitude (Wang et al., 2006; Jiao et al., 2007). To tolerate the degrading

231 environments, anchovy have to reduce the energy devoted for growth and consequently have

232 slower growth. Second, the mis-match of hatching season with the occurrence of optimal

233 conditions might be another factor decelerating fish growth ("match/mismatch hypothesis"; Frank

234 \& Leggett, 1982; Takasuka et al., 2003; Takahashi \& Watanabe, 2004). Due to the influence of

235 the Asian monsoon on runoff in the Yangtze River, water and sediment flowing into in YRE have

236 clear monthly changes (Jiang et al., 2014; Tang et al., 2018). In February, water and sediment

237 reach to the lowest values across the year, decreasing the nutrition supporting the growth of

238 plankton. Anchovy hatching from February therefore have the lower growth rate due to lower

239 temperature and insufficient food. Third, variations of intrinsic attributes among populations

240 would also contribute to the difference in early growth. Growth rates of fish are determined by the

241 interplay of phenotypic plasticity and genetic adaptivity (Conover \& Present, 1990; Sexton et al.,

242 2002; Liu et al., 2015). Across the northwestern Pacific Ocean, there might be substantial

243 differences in phenotypic and genetic attributes among populations in Japan, YRE and Taiwan,

244 causing unregular spatial patterns in growth rates. Overall, the lower growth rates will contribute

245 to smaller length of anchovy in YRE by the end of the first growth season, finally decreasing

246 overwinter survival rates and the strength of population recruitment (Amara et al., 2007; Amara

247 et al., 2009). Future strategies on conserving anchovy resources should take the inter-population

248 variations in early growth into account to accelerate population recruitment.

249 Later hatching onset of anchovy in higher latitude reveals their shorter first growing season, 
250 which is in accordance with the pattern of "counter-gradient variation". The decrease in length of

251 growing season is applicable for other marine fishes, such as Menidia menidia (Conover \&

252 Present, 1990) and Morone saxatilis (Conover et al., 1997). Changes in environmental factors

253 might be the main driver for variations of hatching onset. In the higher latitude, lower water

254 temperature and shorter daytime contribute to the lower metabolic rate and growth rates, impeding

255 the maturation and reproduction of fish (Conover \& Present, 1990; Tarkan, 2006; Benejam et al.,

256 2009; Carmona-Catot et al., 2011). Additionally, lower temperature decelerates gonad

257 development by depressing the growth of plankton and copepods (Hwang et al., 2006; Tanaka et

258 al., 2008). Delayed maturation and spawning therefore result in the later fish hatching in higher

259 latitude. Given the wide distribution of anchovy across the northwestern Pacific Ocean, variations

260 in hatching onset among populations should be integrated into management strategies of anchovy

261 resources to better back-calculate the spawning season and predict dynamics of population

262 recruitment.

263 Intensifying anthropogenic activities and environmental pollutions are threatening the

264 function of estuarine ecosystems (Gilliers et al., 2006; Amara et al., 2009; Bacheler et al., 2009).

265 Elucidating the influence of environmental changes on fish early life history traits is crucial for

266 estimating year-class strength of population recruitment and annual fishery resources (Wang \&

267 Tzeng, 1999; Takasuka et al., 2007). Our results suggest that shifts in hatching dates and growth

268 patterns play a key role on anchovy adaptivity in YRE and across the northwestern Pacific Ocean.

269 In consideration of the increasing impacts of climate changes and habitat modifications on 
270 estuarine ecosystems (Zhou et al., 2008; Zhang et al., 2009), future researches should quantify the

271 influence of different environmental factors on anchovy early growth to provide useful

272 information on restoring anchovy resources and conserving fish diversity in YRE and other

273 estuaries.

\section{ACKNOWLEDGEMENTS}

275 We thank Yushun Chen and three anonymous reviewers for their helpful comments on the

277 of an English text of a draft of this manuscript. 
278

279

280

281

282

283

284

285

286

287

288

289

290

291

292

293

294

295

296

297

\section{REFERENCES}

Amara R, Meziane T, Gilliers C, Hermel G, and Laffargue P. 2007. Growth and condition indices in juvenile sole Solea solea measured to assess the quality of essential fish habitat. Marine Ecology Progress Series 351:201-208.

Amara R, Selleslagh J, Billon G, and Minier C. 2009. Growth and condition of 0-group European flounder, Platichthys flesus as indicator of estuarine habitat quality. Hydrobiologia 627:87-98.

Bacheler NM, Paramore LM, Buckel JA, and Hightower JE. 2009. Abiotic and biotic factors influence the habitat use of an estuarine fish. Marine Ecology Progress Series 377:263277.

Benejam L, Alcaraz C, Sasal P, Simon-Levert G, and García-Berthou E. 2009. Life history and parasites of the invasive mosquitofish (Gambusia holbrooki) along a latitudinal gradient. Biological Invasions 11:2265-2277.

Bowman AW, and Azzalini A. 2014. R package 'sm': nonparametric smoothing methods (version 2.2-5.4)

URL http://www.stats.gla.ac.uk/ adrian/sm, http://azzalini.stat.unipd.it/Book_sm.

Campana SE. 1990. How reliable are growth back-calculations based on otoliths? Canadian Journal of Fisheries and Aquatic Sciences 47:2219-2227.

Carmona-Catot G, Benito J, and García-Berthou E. 2011. Comparing latitudinal and upstream-downstream gradients: life history traits of invasive mosquitofish. Diversity and 
Distributions 17:214-224.

299

317 Gilliers C, Le Pape O, Désaunay Y, Morin J, Guérault D, and Amara R. 2006. Are growth

Chai C, Yu Z, Song X, and Cao X. 2006. The Status and Characteristics of Eutrophication in the Yangtze River (Changjiang) Estuary and the Adjacent East China Sea, China. Hydrobiologia 563:313-328.

Chen C-S, and Chiu T-S. 2003. Early Life History Traits of Japanese Anchovy in the Northeastern Waters of Taiwan, with Reference to Larval Transport. Zoological Studies 42:248-257.

Chiu TS, and Chen CS. 2001. Growth and temporal variation of two Japanese anchovy cohorts during their recruitment to the East China Sea. Fisheries Research 53:1-15.

Conover DO, Brown JJ, and Ehtisham A. 1997. Countergradient variation in growth of young striped bass (Morone saxatilis) from different latitudes. Canadian Journal of Fisheries and Aquatic Sciences 54:2401-2409.

Conover DO, and Present TMC. 1990. Countergradient variation in growth rate: compensation for length of the growing season among Atlantic silversides from different latitudes. Oecologia 83:316-324.

Frank KT, and Leggett WC. 1982. Environmental Regulation of Growth Rate, Efficiency, and Swimming Performance in Larval Capelin (Mallotus villosus), and its Application to the Match/Mismatch Hypothesis. Canadian Journal of Fisheries and Aquatic Sciences 39:691699. 
and density quantitative indicators of essential fish habitat quality? An application to the common sole Solea solea nursery grounds. Estuarine, Coastal and Shelf Science 69:96106.

321

Hsieh CH, Chen CS, Chiu TS, Lee KT, Shieh FJ, Pan JY, and Lee MA. 2009. Time series analyses reveal transient relationships between abundance of larval anchovy and environmental variables in the coastal waters southwest of Taiwan. Fisheries Oceanography 18:102-117.

Hwang SD, Song MH, Lee TW, McFarlane GA, and King JR. 2006. Growth of larval Pacific anchovy Engraulis japonicus in the Yellow Sea as indicated by otolith microstructure analysis. Journal of Fish Biology 69:1756-1769.

Iseki K, and Kiyomoto Y. 1997. Distribution and settling of Japanese anchovy (Engraulis japonicus) eggs at the spawning ground off Changjiang River in the East China Sea. Fisheries Oceanography 6:205-210.

Itoh S, Saruwatari T, Nishikawa H, Yasuda I, Komatsu K, Tsuda A, Setou T, and Shimizu M. 2011. Environmental variability and growth histories of larval Japanese sardine (Sardinops melanostictus) and Japanese anchovy (Engraulis japonicus) near the frontal area of the Kuroshio. Fisheries Oceanography 20:114-124.

Jiang Z, Liu J, Chen J, Chen Q, Yan X, Xuan J, and Zeng J. 2014. Responses of summer phytoplankton community to drastic environmental changes in the Changjiang (Yangtze River) estuary during the past 50 years. Water Research 54:1-11. 
338 Jiao N, Zhang Y, Zeng Y, Gardner WD, Mishonov AV, Richardson MJ, Hong N, Pan D, Yan X-H, Jo Y-H, Chen C-TA, Wang P, Chen Y, Hong H, Bai Y, Chen X, Huang B, Deng H, Shi Y, and Yang D. 2007. Ecological anomalies in the East China Sea: Impacts of the Three Gorges Dam? Water Research 41:1287-1293.

Kim J, and Lo NCH. 2001. Temporal variation of seasonality of egg production and the spawning biomass of Pacific anchovy, Engraulis japonicus, in the southern waters of Korea in 19831994. Fisheries Oceanography 10:297-310.

Li Y, Shen Z, Xian W, and Liu S. 2015. Structure characteristics of nutrients and their restrictive effect on phytoplankton in the Yangtze River Estuary Marine Sciences 39:125-134.

347 Liu C, Chen Y, Olden JD, He D, Sui X, and Ding C. 2015. Phenotypic shifts in life history traits influence invasion success of Goldfish in the Yarlung Tsangpo River, Tibet. Transactions of the American Fisheries Society 144:602-609.

R Development Core Team. 2014. $R$ : a language and environment for statistical computing. $\mathrm{R}$ Foundation for Statistical Computing, Vienna, Austria. Available at: http://Rproject. org. (accessed 23 December 2016).

Searcy PS, and Sponaugle S. 2000. Variable larval growth in a coral reef fish. Marine Ecology Progress Series 206:213-226.

Sexton JP, McKay JK, and Sala A. 2002. Plasticity and genetic diversity may allow saltcedar to invade cold climates in North America. Ecological Applications 12:1652-1660.

357 Starrs D, Ebner BC, and Fulton CJ. 2016. All in the ears: unlocking the early life history biology 
and spatial ecology of fishes. Biological Reviews 91:86-105.

359

Takahashi M, and Watanabe Y. 2004. Growth rate-dependent recruitment of Japanese anchovy Engraulis japonicus in the Kuroshio-Oyashio transitional waters. Marine Ecology Progress Series 266:227-238.

Takahashi M, Watanabe Y, Kinoshita T, and Watanabe C. 2001. Growth of larval and early juvenile Japanese anchovy, Engraulis japonicus, in the Kuroshio-Oyashio transition region. Fisheries Oceanography 10:235-247.

Takasuka A, and Aoki I. 2006. Environmental determinants of growth rates for larval Japanese anchovy Engraulis japonicus in different waters. Fisheries Oceanography 15:139-149.

Takasuka A, Aoki I, and Mitani I. 2003. Evidence of growth-selective predation on larval Japanese anchovy Engraulis japonicus in Sagami Bay. Marine Ecology Progress Series 252:223-238.

Takasuka A, Oozeki Y, and Aoki I. 2007. Optimal growth temperature hypothesis: Why do anchovy flourish and sardine collapse or vice versa under the same ocean regime? Canadian Journal of Fisheries and Aquatic Sciences 64:768-776.

Tanaka H, Takasuka A, Aoki I, and Ohshimo S. 2008. Geographical variations in the trophic ecology of Japanese anchovy, Engraulis japonicus, inferred from carbon and nitrogen stable isotope ratios. Marine Biology 154:557-568.

Tang J, Li Q, and Chen J. 2018. Summertime runoff variations and their connections with Asian summer monsoons in the Yangtze River basin. Journal of Water and Climate Change 9:89- 
100.

379

Tarkan AS. 2006. Reproductive ecology of two cyprinid fishes in an oligotrophic lake near the southern limits of their distribution range. Ecology of Freshwater Fish 15:131-138.

Tsuji S, and Aoyama T. 1984. Daily growth increments in otoliths of Japanese anchovy larvae Engraulis japonica. Bulletin of the Japanese Society of Scientific Fisheries 50:1105-1108.

Wan R, and Bian X. 2012. Size variability and natural mortality dynamics of anchovy Engraulis japonicus eggs under high fishing pressure. Marine Ecology Progress Series 465:243-251.

Wang Y, Liu Q, and Ye Z. 2006. A Bayesian analysis on the anchovy stock (Engraulis japonicus) in the Yellow Sea. Fisheries Research 82:87-94.

Wang YT, and Tzeng WN. 1999. Differences in growth rates among cohorts of Encrasicholina punctifer and Engraulis japonicus larvae in the coastal waters off Tanshui River Estuary, Taiwan, as indicated by otolith microstructure analysis. Journal of Fish Biology 54:10021016.

Xing J, Xian W, and Shen X. 2014. Distribution and Source of Particulate Organic Carbon and Particulate Nitrogen in the Yangtze River Estuary in Summer 2012. Environmental Science 35:2520-2527.

Yasue N, and Takasuka A. 2009. Seasonal variability in growth of larval Japanese anchovy Engraulis japonicus driven by fluctuations in sea temperature in the Kii Channel, Japan. Journal of Fish Biology 74:2250-2268.

Yu H, and Xian W. 2009. The environment effect on fish assemblage structure in waters adjacent 

and Limnology 27:443-456.

400

401

Zenitani H, Kono N, Tsukamoto Y, and Masuda R. 2009. Effects of temperature, food availability, and body size on daily growth rate of Japanese anchovy Engraulis japonicus larvae in Hiuchi-nada. Fisheries Science 75:1177-1188.

Zhang W, Feng H, Chang J, Qu J, Xie H, and Yu L. 2009. Heavy metal contamination in surface sediments of Yangtze River intertidal zone: An assessment from different indexes. Environmental Pollution 157:1533-1543.

Zhao X, Hamre J, Li F, Jin X, and Tang Q. 2003. Recruitment, sustainable yield and possible ecological consequences of the sharp decline of the anchovy (Engraulis japonicus) stock in the Yellow Sea in the 1990s. Fisheries Oceanography 12:495-501.

Zhou M, Shen Z, and Yu R. 2008. Responses of a coastal phytoplankton community to increased nutrient input from the Changjiang (Yangtze) River. Continental Shelf Research 28:14831489.

Zhu J, Zhao X, and Li F. 2007. Growth characters of the anchovy stock in the Yellow Sea with its annual and seasonal variations. Marine Fisheries Research 28:64-72. 


\section{FIGURE CAPTIONS}

416 FIGURE 1 Trends in sea surface temperature (SST) at Stations 29 and 30 during growing

417 season of anchovy in the Yangtze River Estuary. Anchovy in each station were divided into three

418 groups (Early, Middle and Late) based on their hatching dates, which were shown in X axis.

419 FIGURE 2 Frequency distributions of (A) standard lengths of anchovy at Station 29; (B)

420 standard lengths of anchovy at Station 30; (C) hatching dates of anchovy at Station 29; (D)

421 hatching dates of anchovy at Station 30.

422 FIGURE 3 Mean growth trajectories of anchovy in three groups at (A) Station 29; (B) Station

423 30. Growth rates were back-calculated from increment widths in otolith microstructure using the

424 biological intercept method. Days where anchovy numbers were less than five were excluded. 
425 TABLE 1. Number (N), standard length, hatching date and mean growth rate of anchovy from

426 three groups at the Stations 29 and 30 in the Yangtze River Estuary. Three groups were divided

427 according to individual hatching dates. Hatching date and growth rate were back-calculated from

428 the number and width of increments deposited in otolith section.

429 TABLE 2. Distribution, standard length, hatching onset and mean growth rate of anchovy in

430 populations from Taiwan, the Yangtze River Estuary and Japan.

431 


\section{SUPPORTING INFORMATION}

433 Supplement 1: Data of environmental factors in 40 stations in the Yangtze River Estuary in May,

434 2012. Station of 1, 2, 5, 6 and 9 were not accessed due to the lower depth.

435 Supplement 2: Data of daily sea surface temperatures (SST) at Station 29 and 30 during growing 436 seasons of anchovy in the Yangtze River Estuary.

437 Supplement 3: Standard length $(\mathrm{mm})$, weight $(\mathrm{g})$, increment number and width of each increment $438(\mu \mathrm{m})$ for each anchovy at Station 29 and 30. 
Figure 1

Changes in sea surface temperature (SST).

Trends in sea surface temperature (SST) at Stations 29 and 30 during growing season of anchovy in the Yangtze River Estuary. Anchovy in each station were divided into three groups (Early, Middle and Late) based on their hatch dates, which were shown in $\mathrm{X}$ axis.

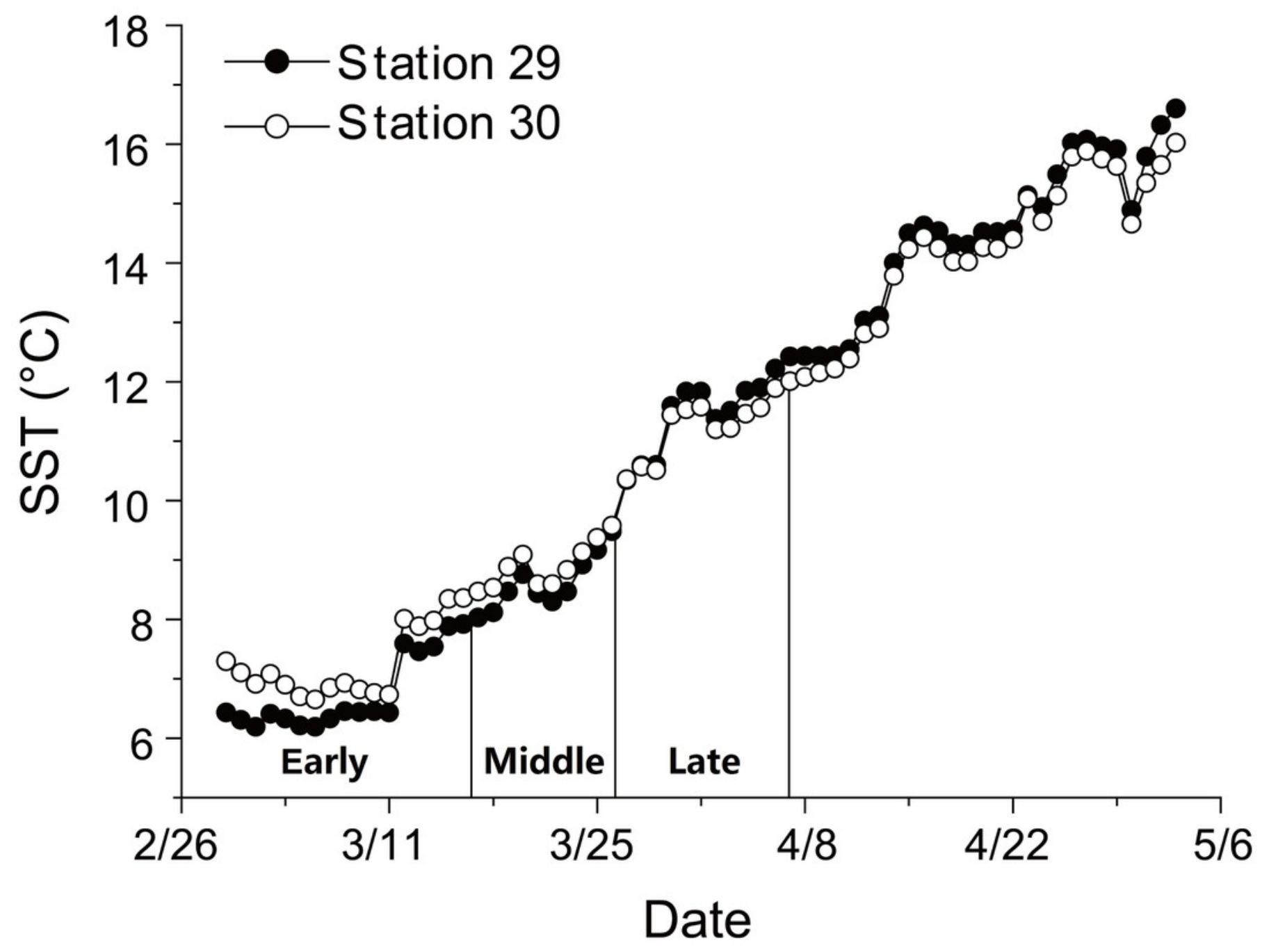




\section{Figure 2}

Distributions of standard length and hatching date.

Frequency distributions of (A) standard lengths of anchovy at Station 29; (B) standard lengths of anchovy at Station 30; (C) hatching dates of anchovy at Station 29; (D) hatching dates of anchovy at Station 30.

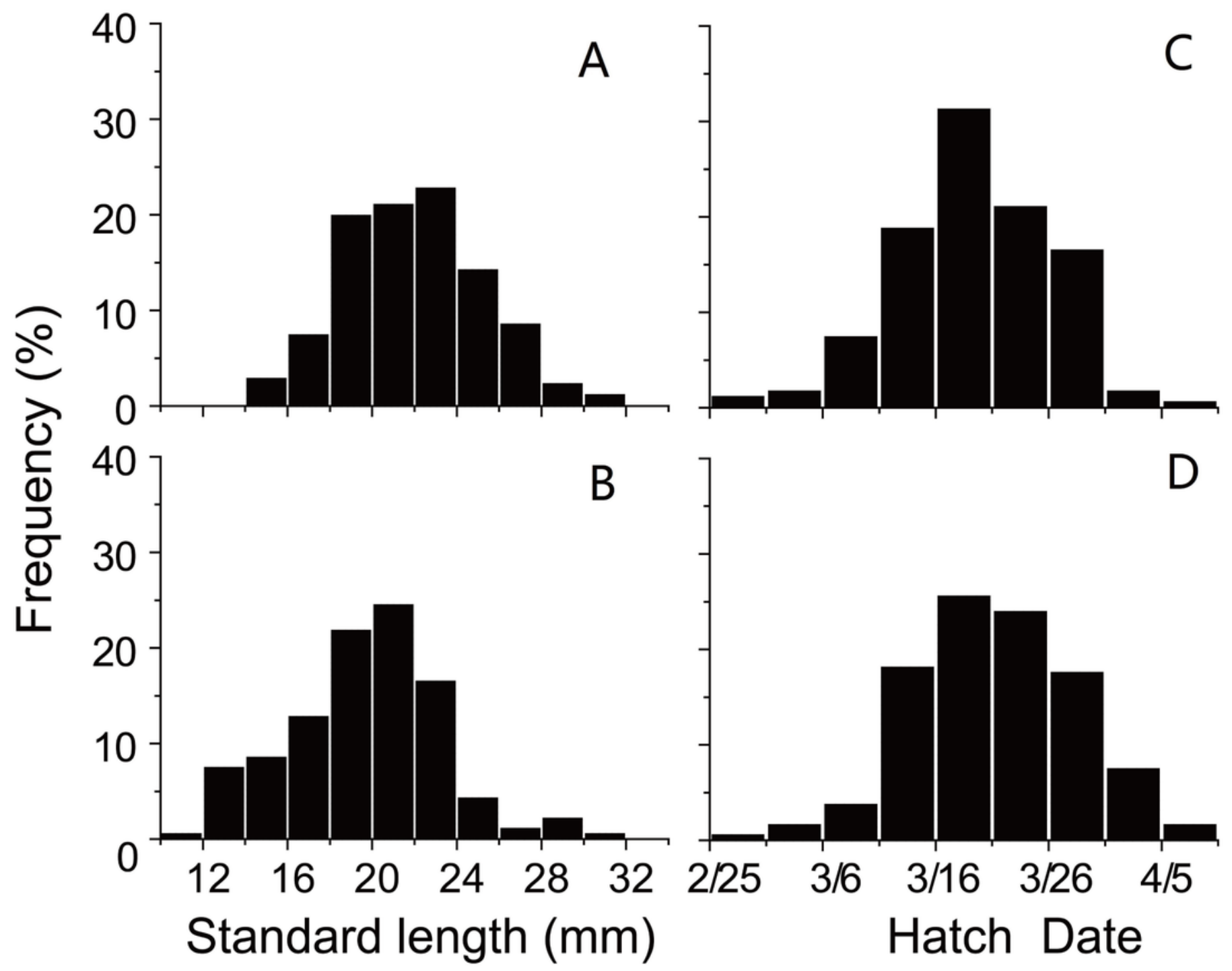




\section{Figure 3}

Growth trajectories of anchovy.

Mean growth trajectories of anchovy from three groups at Stations 29 and 30 (excluding days where anchovy numbers were less than five). Growth rates were back-calculated from increment widths in otolith microstructure using the biological intercept method. 


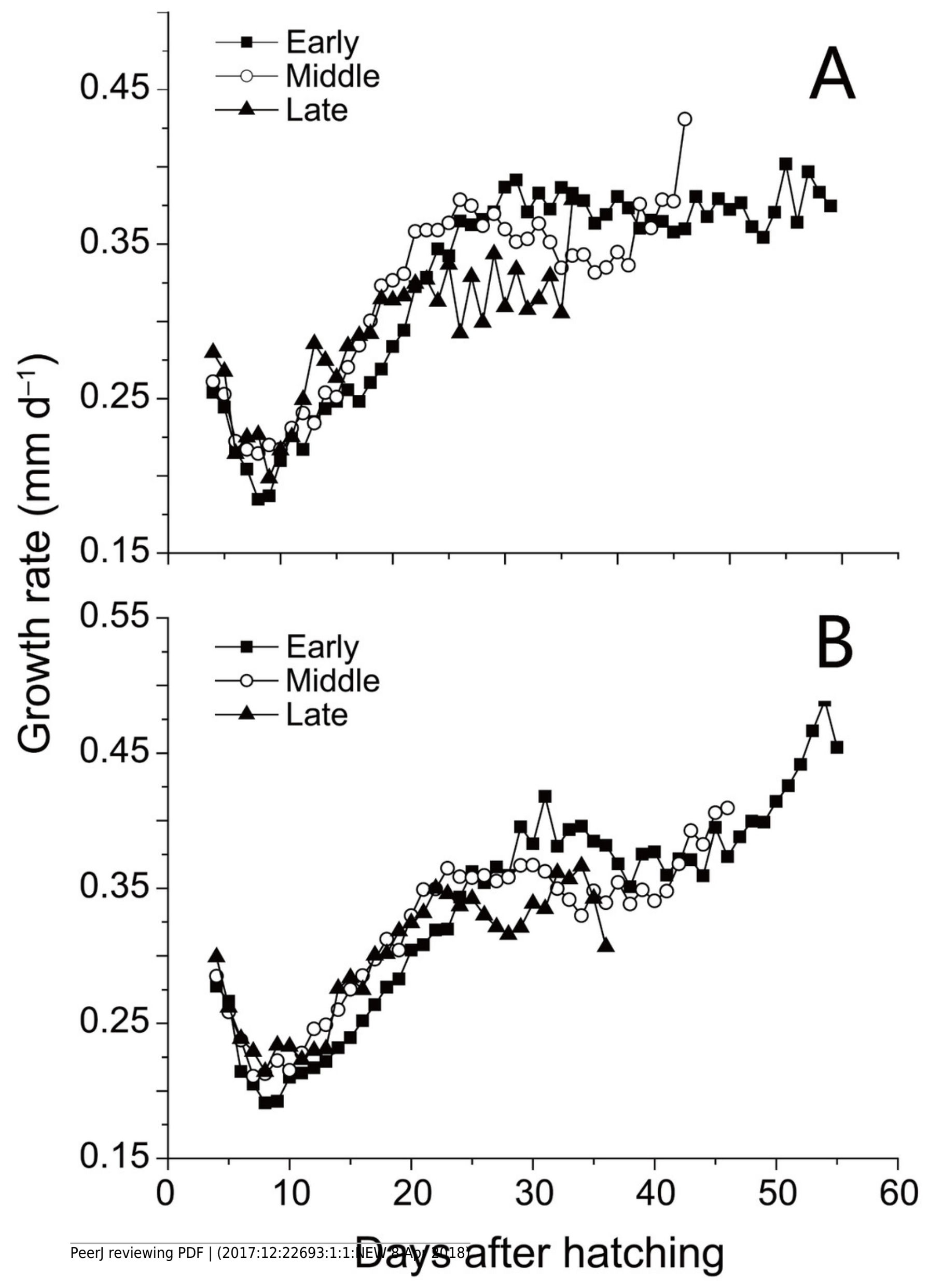




\section{Table $\mathbf{1}$ (on next page)}

Biological data of anchovy.

Number (N), standard length, hatching date and mean growth rate of anchovy from three groups at the Stations 29 and 30 in the Yangtze River Estuary. Three groups were divided according to individual hatch dates. Hatching date and growth rate were back-calculated from the number and width of increments deposited in otolith section. 


\begin{tabular}{cccccccc}
\hline \multirow{2}{*}{ Station } & Group & $\mathrm{N}$ & \multicolumn{2}{c}{ Standard length $(\mathrm{mm})$} & \multirow{2}{*}{ Hatching date } & \multicolumn{2}{c}{ Mean growth rate $\left(\mathrm{mm} \mathrm{d}^{-1}\right)$} \\
& & & Mean & Range & & Mean & Range \\
\hline 29 & Early & 51 & 22.67 & $16.72-32.00$ & $2 / 26-3 / 16$ & 0.38 & $0.27-0.55$ \\
29 & Middle & 96 & 19.63 & $12.93-29.27$ & $3 / 17-3 / 26$ & 0.46 & $0.30-0.59$ \\
29 & Late & 41 & 15.90 & $11.07-20.87$ & $3 / 27-4 / 6$ & 0.51 & $0.37-0.77$ \\
& & & & & & & \\
30 & Early & 55 & 24.59 & $18.81-30.12$ & $2 / 28-3 / 16$ & 0.41 & $0.29-0.56$ \\
30 & Middle & 94 & 21.47 & $14.62-28.63$ & $3 / 17-3 / 26$ & 0.50 & $0.38-0.68$ \\
30 & Late & 27 & 17.93 & $14.02-21.87$ & $3 / 30-4 / 5$ & 0.55 & $0.42-0.73$ \\
\hline
\end{tabular}




\section{Table 2 (on next page)}

Information of three anchovy populations.

Distribution, standard length, hatching onset and mean growth rate of anchovy in populations from Taiwan, the Yangtze River Estuary and Japan. 


\begin{tabular}{|c|c|c|c|c|c|c|c|}
\hline \multirow{2}{*}{ Region } & \multirow{2}{*}{ Latitude } & \multicolumn{2}{|c|}{ Standard length (mm) } & \multirow{2}{*}{$\begin{array}{c}\text { Hatching } \\
\text { onset }\end{array}$} & \multicolumn{2}{|c|}{ Mean growth rate $\left(\mathrm{mm} \mathrm{d}^{-1}\right)$} & \multirow{2}{*}{ Source } \\
\hline & & Minimum & Maximum & & Minimum & Maximum & \\
\hline Taiwan & $24-25^{\circ} \mathrm{N}$ & 17.2 & 31.3 & $2 / 12$ & 0.37 & 0.91 & Chiu and Chen (2001) \\
\hline The Yangtze River Estuary & $30-31^{\circ} \mathrm{N}$ & 11.07 & 32 & $2 / 26$ & 0.2 & 0.46 & Present study \\
\hline Japan & $35-40^{\circ} \mathrm{N}$ & 20 & 35 & $3 / 3$ & 0.49 & 0.71 & Takahashi et al. (2001) \\
\hline
\end{tabular}

